\title{
Physiological effects of flow and pressure triggering during non-invasive mechanical ventilation in patients with chronic obstructive pulmonary disease
}

\author{
Stefano Nava, Nicolino Ambrosino, Claudio Bruschi, Marco Confalonieri, Ciro Rampulla
}

\begin{abstract}
Background - The effect of the type of trigger system on inspiratory effort has been studied in intubated patients, but no data are available in non-invasive mechanical ventilation where the "trigger variable" may be even more important since assisted modes of ventilation are often employed from the beginning of mechanical ventilation.

Methods - The effect of flow triggering ( 1 and $5 \mathrm{l} / \mathrm{min}$ ) and pressure triggering $\left(-1 \mathrm{~cm} \mathrm{H}_{2} \mathrm{O}\right)$ on inspiratory effort during pressure support ventilation (PSV) and assisted controlled mode (A/C) delivered non-invasively with a full face mask were compared in patients with chronic obstructive pulmonary disease (COPD) recovering from an acute exacerbation. The patients were studied during randomised $\mathbf{1 5}$ minute runs at zero positive end expiratory pressure (ZEEP). The oesophageal pressure time product (PTPoes), dynamic intrinsic PEEP (PEEPi,dyn), fall in maximal airway pressure ( $\triangle \mathrm{Paw}$ ) during inspiration, and ventilatory variables were measured.
\end{abstract}

Results - Minute ventilation, respiratory pattern, dynamic lung compliance and resistances, and changes in end expiratory lung volume ( $\triangle E E L V)$ were the same with the two triggering systems. The total PTPoes and its pre-triggering phase (PTP due to PEEPi and PTP due to valve opening) were significantly higher during both PSV and $A / C$ with pressure triggering than with flow triggering at both levels of sensitivity. $\triangle P$ aw was larger during pressure triggering, and PEEPi,dyn was significantly reduced during flow triggering in the A/C mode only.

Conclusions - In patients with COPD flow triggering reduces the inspiratory effort during both PSV and $\mathrm{A} / \mathrm{C}$ modes compared with pressure triggering. These findings are likely to be due to a reduction in PEEPi,dyn and in the time of valve opening with a flow trigger.

(Thorax 1997;52:249-254)

Keywords: chronic obstructive pulmonary disease, mechanical ventilation, flow triggering, pressure triggering.

It has been clearly and repeatedly shown that non-invasive mechanical ventilation (NIMV) can reduce the need for endotracheal intubation $^{1-4}$ and the length of stay in hospital in "selected" patients 5 with chronic obstructive pulmonary disease (COPD) and acute respiratory failure. The partial or total unloading of respiratory muscles is very important, especially during the first period of NIMV, in order to reduce the central respiratory drive and to obtain a satisfactory blood gas exchange. Several physiological studies have shown that NIMV may significantly unload the respiratory muscles, at the same time reducing the work of breathing performed by the patient. ${ }^{16-8}$ Most of the published papers studied assisted or spontaneous modalities of ventilation in these non-intubated patients since they seem to be better tolerated and are less likely to cause patient-ventilator mismatching as the patients are not usually sedated or paralysed for safety reasons. Most ventilators are equipped with pressure triggers but systems based on flow triggers have recently been proposed. Some studies in intubated patients have suggested that this trigger is more effective than a pressure trigger in reducing the work of the inspiratory muscles. ${ }^{9-12}$ In NIMV the "trigger variable" may be even more relevant since the patients are required to control the beginning of inspiration. However, to date no reports have been published concerning this problem. The aim of this study was to compare the influence of flow triggers and pressure triggers on the inspiratory effort in patients with COPD during two assisted modes of NIMV (assisted control mode $(\mathrm{A} / \mathrm{C})$ and pressure support (PSV)).

\section{Methods}

PATIENTS

Eight patients with COPD who required noninvasive mechanical ventilation with a face mask for an acute exacerbation of their disease were studied after giving oral consent to a protocol approved by the ethics committee of the S. Maugeri Foundation of Pavia. The precipitating cause of acute respiratory failure was respiratory tract infection without radiological evidence of pneumonia. The characteristics of these patients are given in table 1 . The study was performed when the patients were clinically stable, as defined elsewhere, ${ }^{13}$ and ready to be weaned.

\section{MEASUREMENTS}

Static and dynamic lung volumes were measured using a water spirometer (Biomedin, 
Table 1 Characteristics of the patients with chronic obstructive pulmonary disease

\begin{tabular}{|c|c|c|c|c|c|c|c|}
\hline Subject no. & Age (years) & $F E V_{1}(\%$ pred $)$ & $F E V / F V C(\%)$ & $p H$ & $\mathrm{PaCO}_{2}(k \mathrm{~Pa})$ & $\mathrm{PaO}_{2} / \mathrm{FiO}_{2}$ & $M I P\left(\mathrm{~cm} \mathrm{H} \mathrm{H}_{2} \mathrm{O}\right)$ \\
\hline 1 & 71 & 38 & 42 & 7.43 & 4.68 & 212 & 38 \\
\hline 2 & 66 & 51 & 69 & 7.47 & 4.22 & 232 & 65 \\
\hline 3 & 58 & 23 & 38 & 7.38 & 5.67 & 189 & 52 \\
\hline 4 & 72 & 43 & 55 & 7.36 & 5.33 & 222 & NA \\
\hline 5 & 69 & NA & NA & 7.42 & 4.56 & 175 & 42 \\
\hline 6 & 74 & 29 & 44 & 7.35 & 5.75 & 139 & 30 \\
\hline 7 & 69 & NA & NA & 7.44 & 4.91 & 190 & 55 \\
\hline 8 & 66 & 35 & 52 & 7.42 & 4.88 & 183 & 45 \\
\hline
\end{tabular}

$\mathrm{FEV}_{1}=$ forced expiratory volume in one second $\mathrm{FVC}=$ forced vital capacity; $\mathrm{PacO}_{2}, \mathrm{PaO}_{2}=$ arterial carbon dioxide and oxygen tensions; $\mathrm{FiO}_{2}=$ fractional inspired oxygen; $\mathrm{MIP}=$ maximum inspiratory pressure; $\mathrm{NA}=$ not available. Arterial blood gas tensions were recorded during mechanical ventilation.

Padova, Italy) with the patient seated. Arterial blood gases from the radial artery were studied with a blood gas analyser (ABL 300 Radiometer, Copenhagen, Denmark).

Flow (V) was measured with a heated pneumotachograph (Screenmate Box 0586, Jaeger $\mathrm{GmbH}$, Hochberg, Germany) connected to a differential pressure transducer $\left( \pm 2 \mathrm{~cm} \mathrm{H}_{2} \mathrm{O}\right)$, and tidal volume was determined by numerical integration of flow. The pneumotachograph was inserted between the face mask and the "Y" of the ventilator tubings. The following variables were obtained from the pneumotachograph: tidal volume $(\mathrm{Vt})$, respiratory rate (RR), total minute ventilation (Ve) as the product of $\mathrm{Vt}$ and $\mathrm{f}$, inspiratory ( $\mathrm{Ti}$ ) and expiratory (Te) time, total breath duration (Ttot), and the mean inspiratory flow $(\mathrm{Vt} / \mathrm{Ti})$.

Changes in oesophageal (Poes) and gastric (Pga) (only in four patients) pressures were measured using two balloons positioned in the stomach and in the middle third of the oesophagus, respectively, and connected by catheters to two differential pressure transducers (Honeywell $\pm 250 \mathrm{~cm} \mathrm{H}_{2} \mathrm{O}$, Freeport, Illinois, USA). This allowed the transdiaphragmatic pressure (Pdi) to be computed by subtraction of Poes from Pga. The position of the oesophageal balloon was checked using the occlusion test. ${ }^{14}$ Another similar catheter and pressure transducer were employed to record the pressure at the airway opening (Paw) through a side port inserted between the face mask and the pneumotachograph. Transpulmonary pressure $(\mathrm{PL})$ was obtained by subtracting Poes from Paw, while the maximal fall in airway pressure $(\Delta \mathrm{Paw})$ during inspiration was measured from the end positive airway pressure. The pressure swings were analysed by measuring peak amplitude from the immediate preceding baseline values. PL was used to calculate dynamic lung compliance (Cdyn) according to the MeadWittenberger method. ${ }^{15}$ Changes in end expiratory lung volumes $(\triangle \mathrm{EELV})$ were determined by multiplying the changes in end expiratory PL $(\triangle \mathrm{EEPL})$ and Cdyn at each step of the experimental procedure $(\triangle \mathrm{EELV}=$ $\triangle$ EEPL $\times$ Cdyn). ${ }^{16}$

Dynamic PEEPi (PEEPi,dyn) was measured in four patients as the amount of negative deflection in Poes preceding the start of inspiratory flow from which the decrease in Pga, if any, during this time interval was subtracted. ${ }^{8}$ In the remaining patients the PEEPi,dyn was only recorded from the Poes trace.
The pressure-time integral of the diaphragm (PTPdi) and of the inspiratory muscles (PTPoes) was calculated on a breath by breath basis. The former was measured as the area subtended by Pdi above end expiratory baseline over $\mathrm{Ti}$ and the latter as the area subtended by Poes and the chest wall static recoil pressuretime curve over $\mathrm{Ti}$, taking into account the PEEPi. ${ }^{17}$ The chest wall static recoil pressuretime curve was extrapolated from the static volume-pressure curve of the chest wall of normal subjects. The PTPtot was then divided into: (1) the PTP of the triggering phase and (2) the PTP of the post-triggering phase. ${ }^{18}$ The former is the area under the pressure signal from the onset of its negative deflection to the point corresponding to the onset of inspiratory flow, referred to the chest wall static recoil pressure-time curve. It can be further divided into two parts: (a) PTPoes-PEEPi, defined as the area subtended by the pressure curve between the onset of its negative deflection and the point corresponding to the zero flow; and (b) the effort of the inspiratory muscles required to open the inspiratory valve, calculated as the area subtended by the pressure curve between the first zero flow value and the last zero flow or, in cases in which this was not perfectly clear, the moment preceding the abrupt change in flow towards inspiration, corresponding to the maximum negative Paw. The post-triggering PTP was obtained from the difference between PTPtot and PTP of the triggering phase. Figure 1 illustrates these different triggering phases.

Subjective compliance with ventilation by the patients was recorded by an arbitrary scale and defined as: $1=$ bad, $2=$ quite bad, $3=$ sufficient, $4=$ good, and $5=$ very good.

\section{STUDY PROTOCOI}

Subjects were studied in the semisupine position with an airtight facial mask (Gibeck Respiration AB, Upplands-Vasby, Sweden) strapped to the face. The cushion of the mask was inflated with about $20 \mathrm{ml}$ of air to adhere perfectly to the patient's face and particular care was taken to avoid any possible air leaks. The patients were asked to relax completely, even if they were used to this modality of ventilation.

The patients were randomly submitted to trial of 15 minutes each with different trigger functions in both $\mathrm{A} / \mathrm{C}$ and PSV modes. At the 


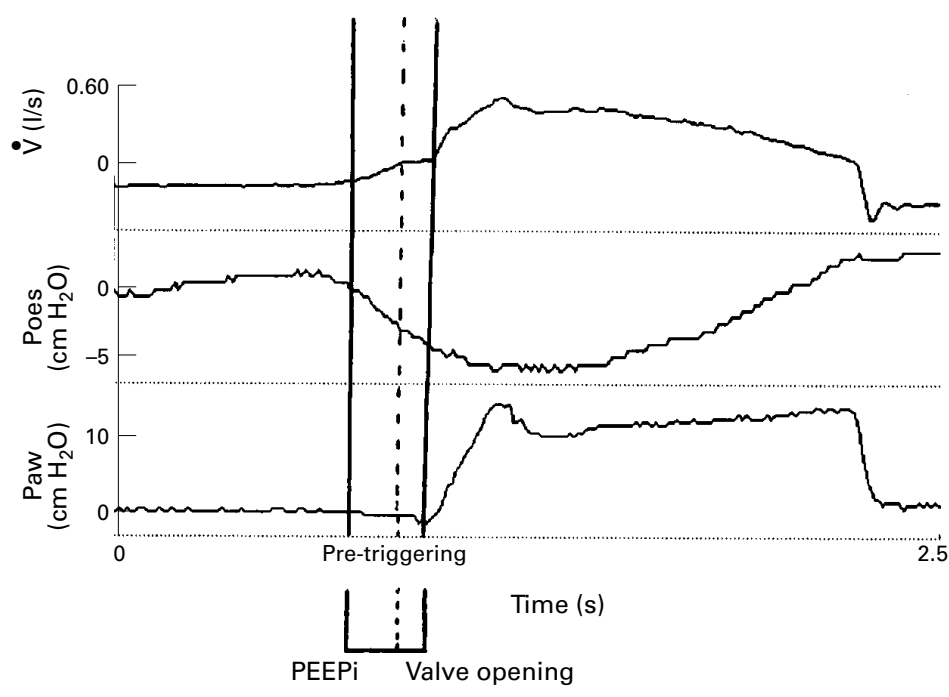

Figure 1 Representative traces of one subject illustrating the various phases of triggering. From top to bottom: flow (V), oesophageal pressure (Poes), and airway pressure (Paw). The two solid lines identify, on the Poes trace, the inspiratory effort produced during the pre-triggering phase. The initial portion of Poes, encompassed between the onset of its negative deflection and the point on Poes corresponding to the first zero flow (dashed line), represents the effort to overcome intrinsic positive end expiratory pressure (PEEPi). The second portion of the Poes trace, between the first zero flow and the point of its abrupt rise (and maximum negative Paw), represents the effort that had to be produced to open the inspiratory valve (valve opening).

beginning of the study (control) and in the interval between different runs the patients were ventilated for five minutes with a demand flow CPAP set at $5 \mathrm{~cm} \mathrm{H}_{2} \mathrm{O}$. This was long enough for all the variables considered to return to their control values.

Mechanical ventilation was delivered by a Bird 8400 STi (Palm Springs, California, USA) which provides both pressure and flow (socalled bias flow) triggering systems. The $\mathrm{FiO}_{2}$ used was $31.2(4.2) \%$.

The different modalities of ventilation were set as follows:

PSV: the level of pressure support was the one set by the attending physician the day before the study and was $13.1(2.3) \mathrm{cm} \mathrm{H}_{2} \mathrm{O}$.

$\mathrm{A} / \mathrm{C}$ : the set tidal volume was titrated to achieve approximately the expired Vt obtained in the same patient during PSV with a constant inspiratory rate. The respiratory rate was fixed at six breaths $/ \mathrm{min}$ to allow the patient to start the inspiration voluntarily in most of the cases.

The trigger function was set using two different mechanisms - flow triggering and pressure triggering.

Flow triggering: the bias flow system adopted by the ventilator used in this study works like a "flow-by" system since it delivers fresh gas continuously within the inspiratory and expiratory circuit at a constant rate that was set in this study at $10 \mathrm{l} / \mathrm{min}$. The flow sensitivity was set at $1 \mathrm{l} / \mathrm{min}$, which is the minimum level obtained with the ventilator used in the present study, and $5 \mathrm{l} / \mathrm{min}$.

Pressure triggering: the threshold pressure value was set at $-1 \mathrm{~cm} \mathrm{H}_{2} \mathrm{O}$ which is the minimum sensitivity allowed by the ventilator used.

Six trials were therefore randomly performed in each patient: (1) A/C with pressure trigger set at $-1 \mathrm{~cm} \mathrm{H}_{2} \mathrm{O}$; (2) $\mathrm{A} / \mathrm{C}$ with flow trigger set at
$1 \mathrm{l} / \mathrm{min}$; (3) A/C with flow trigger set at $5 \mathrm{l} / \mathrm{min}$; (4) $\mathrm{PSV}$ with pressure trigger set at $-1 \mathrm{~cm} \mathrm{H}_{2} \mathrm{O}$; (5) PSV with flow trigger set at $1 \mathrm{l} / \mathrm{min}$; and (6) PSV with flow trigger set at $51 / \mathrm{min}$. Demand valve CPAP $5 \mathrm{~cm} \mathrm{H}_{2} \mathrm{O}$ was applied in the intervals between the trials.

\section{DATA ANALYSIS}

All variables were continuously recorded on an eight channel strip chart recorder (Gould TA 400 Valley View, Ohio, USA) and also passed through an analog to digital converter (Data Translation DT2801/A) to a personal computer (Vectra 386/20N, Hewlett Packard equipped with a math coprocessor) and recorded at a sampling rate of $60 \mathrm{~Hz}$ once a stable breathing pattern had been reached. Fifteen consecutive breaths, usually at the end of each run, were considered for data analysis, except for the ventilatory pattern which was calculated over three minutes.

The results are expressed as mean (SD). Comparisons between different CPAP $5 \mathrm{~cm}$ $\mathrm{H}_{2} \mathrm{O}$ trials were performed using the KruskalWallis test, and the Wilcoxon matched pairs test was used to assess the effects of the different trigger systems within the same mode of ventilation and to compare them with CPAP $5 \mathrm{~cm}$ $\mathrm{H}_{2} \mathrm{O}$. Comparisons between the subjective compliance scores of the patients and ventilation were analysed using the $\chi^{2}$ test of independence. Statistical significance was defined as a two tailed $\mathrm{p}$ value of $<0.05$.

\section{Results}

All the patients tolerated the various trials of ventilation without discomfort, nor were any problems observed in relation to air leaks with either pressure or flow triggers. No significant differences were seen between the various control measurements at CPAP $5 \mathrm{~cm} \mathrm{H}_{2} \mathrm{O}$ performed throughout the experiment. Figure 2 is the identity plot between the PEEPi,dyn recorded using only the Poes trace and that obtained by subtracting from this value the contribution of Pga. A significant contribution

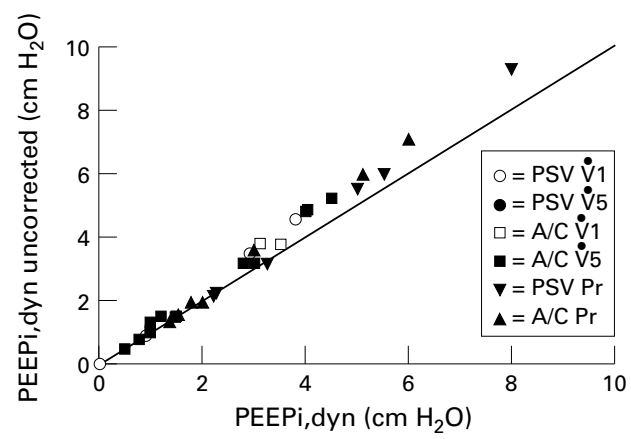

Figure 2 Relationship between values of dynamic intrinsic positive end expiratory pressure (PEEPi,dyn) corrected and uncorrected for expiratory muscle relaxation obtained in four patients with COPD. The symbols are data from each patient during different ventilatory modes. Some points overlap. PSV $=$ pressure support ventilation; $A / C=$ assisted controlled ventilation; $\dot{V} 1, \dot{V} 5=$ flow triggering at $1 \mathrm{l} / \mathrm{min}$ and $5 \mathrm{l} / \mathrm{min} ; \mathrm{Pr}=$ pressure triggering. 
Table 2 Mean (SD) changes in dynamic intrinsic positive end expiratory pressure (PEEPi,dyn) and maximal fall in airway pressure ( $\triangle P a w)$ during various modalities of non-invasive mechanical ventilation

\begin{tabular}{|c|c|c|c|c|c|c|}
\hline \multirow[t]{2}{*}{ Trigger } & \multicolumn{3}{|c|}{ PEEPi,dyn $\left(\mathrm{cm} \mathrm{H}_{2} \mathrm{O}\right)$} & \multicolumn{3}{|c|}{$\triangle P a w\left(\mathrm{~cm} \mathrm{H}_{2} \mathrm{O}\right)$} \\
\hline & PSV & $A / C$ & CPAP & PSV & $A / C$ & $C P A P$ \\
\hline Pressure $\left(1 \mathrm{~cm} \mathrm{H}_{2} \mathrm{O}\right)$ & $6.6(4.1)$ & $5.9(2.9)$ & $5.8(3.8)$ & $2.3(0.7)$ & $2.4(0.3)$ & $2.7(0.6)$ \\
\hline Flow $(1 \mathrm{l} / \mathrm{min})$ & $4.4(3.0)$ & $3.2(1.8) *$ & & $1.0(0.4)^{*}$ & $0.9(0.4)^{*}$ & \\
\hline Flow $(5 \mathrm{l} / \mathrm{min})$ & $4.5(3.2)$ & $3.4(2.2) *$ & & $1.2(0.6) \dagger$ & $1.1(0.5)^{*}$ & \\
\hline
\end{tabular}

$(>15 \%)$ to the PEEPi,dyn from the expiratory muscles was present in only one of four patients, and this remained constant irrespective of the mode of ventilation. For this reason, the PEEPi,dyn in this study was calculated from the Poes trace.

No significant changes were observed in the respiratory variables $(\mathrm{Vt}, \mathrm{Ti}$, $\mathrm{Ttot}, \mathrm{Ti} / \mathrm{Ttot}, \mathrm{Te}$, $\mathrm{Vt} / \mathrm{Ti}$, and respiratory rate) with the different trigger systems. As shown in table 2, a significant reduction in $\triangle \mathrm{Paw}$ and PEEPi,dyn was recorded using the two levels of flow trigger sensitivity ( 1 and $5 \mathrm{l} / \mathrm{min}$ ) but, in the case of $\mathrm{PEEPi}$,dyn, this was only during $\mathrm{A} / \mathrm{C}$. No significant differences were seen in these two parameters between CPAP $5 \mathrm{~cm} \mathrm{H}_{2} \mathrm{O}$ and either $\mathrm{A} / \mathrm{C}$ or PSV with the pressure trigger. The total PTPoes was also significantly reduced using the flow triggers (fig 3) with mean differences (95\% confidence intervals) of 2.51 (1.81 to 5.61 ) between $\mathrm{A} / \mathrm{C}$ pressure trigger and $\mathrm{A} / \mathrm{C}$ flow $1 \mathrm{l} /$ $\min , 2.18$ (0.85 to 5.01$)$ between $\mathrm{A} / \mathrm{C}$ pressure trigger and $\mathrm{A} / \mathrm{C}$ flow $5 \mathrm{l} / \mathrm{min}, 4.07$ (1.29 to 5.75 ) between PSV pressure trigger and PSV flow 11 / min, and 3.64 ( -1.52 to 9.80$)$ between PSV pressure trigger and PSV flow $5 \mathrm{l} / \mathrm{min}$.

In the four subjects in whom Pga was recorded the changes in PTPdi closely followed those in PTPoes since the contribution of PTPga was negligible. In table 3 the total PTPoes has been divided into the pre-triggering phase (PTP-PEEPi and PTP-opening) and the post-triggering phase. A significant decrease was observed for both parts of the pre-triggering phase and also, but to a lesser extent $(\mathrm{p}<0.05)$, for the post-triggering phase during $\mathrm{A} / \mathrm{C}$ trigger at $11 / \mathrm{min}$.

All these PTP values recorded during PSV and $\mathrm{A} / \mathrm{C}$, irrespective of the trigger system used, were significantly less than those observed during CPAP $5 \mathrm{~cm} \mathrm{H}_{2} \mathrm{O}$. Small insignificant changes were recorded for compliance or res-

Table 3 Effect of triggering mode on oesophageal pressure time product (PTPoes) in patients undergoing non-invasive mechanical ventilation

\begin{tabular}{lllll}
\hline & \multicolumn{2}{l}{ PTPoes triggering $\left(\mathrm{cm} \mathrm{H} \mathrm{H}_{2} \mathrm{O} . \mathrm{s}\right)$} & \multirow{2}{*}{$\begin{array}{c}\text { Post-triggering } \\
\left.\text { (cm H } \mathrm{H}_{2} \mathrm{O} . \mathrm{s}\right)\end{array}$} \\
\cline { 2 - 4 } & PEEPi & Opening & PEEPi+opening & \\
\hline PSV pressure & $1.6(0.8)$ & $1.7(0.7)$ & $2.4(1.1)$ & $7.2(3.3)$ \\
PSV flow (1 1/min) & $0.5(0.3)^{*}$ & $0.6(0.4) \dagger$ & $1.4(0.6)^{*}$ & $5.9(4.4)$ \\
PSV flow (5 1/min) & $0.6(0.2)^{*}$ & $0.7(0.4) \dagger$ & $1.5(0.5)^{*}$ & $6.0(3.8)$ \\
A/C pressure & $1.0(0.4)$ & $1.4(0.5)$ & $2.3(0.6)$ & $6.8(2.2)$ \\
A/C flow (1 1/min) & $0.4(0.3) \dagger$ & $0.7(0.3)^{*}$ & $1.2(0.4) \dagger$ & $4.6(1.8) \dagger$ \\
A/C flow (5 1/min) & $0.5(0.2) \dagger$ & $0.9(0.4) \dagger$ & $1.4(1.1) \dagger$ & $5.1(3.3)$ \\
CPAP & $2.7(0.4)$ & $1.9(0.5)$ & $4.6(1.1)$ & $9.8(4.4)$
\end{tabular}

$\mathrm{PEEPi}=$ dynamic intrinsic positive end expiratory pressure; $\mathrm{PSV}=$ pressure support ventilation; $\mathrm{A} / \mathrm{C}=$ assisted controlled mode $; \mathrm{CPAP}=$ continuous positive airway pressure

$* \mathrm{p}<0.01$, flow trigger ( 1 and $51 / \mathrm{min}$ ) versus pressure trigger.

$+\mathrm{p}<0.05$, flow trigger $(1$ and $51 / \mathrm{min}$ ) versus pressure trigger.
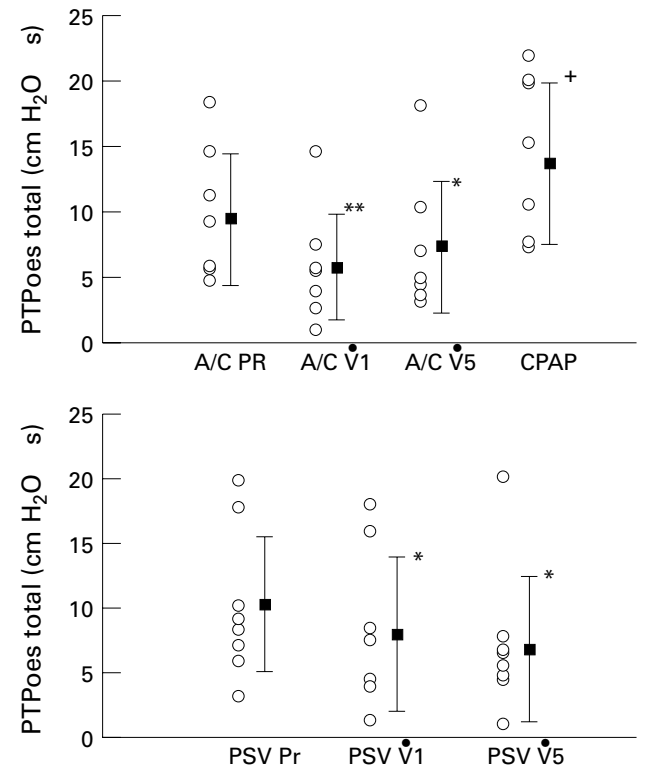

Figure 3 Individual and mean (SD) values of the "total" oesophageal pressure time product (PTPoes) during the various ventilatory modes in patients with COPD non-invasively ventilated. Some points overlap. ${ }^{*} p<0.05$, ${ }_{* *}^{*} p<0.01, A / C \operatorname{Pr}$ versus $A / C$ V 1 or $V 5 ;+p<0.05, A / C$ versus $C P A P$. PSV $=$ pressure support ventilation; $A / C=$ assisted controlled ventilation; $\dot{V} 1, \dot{V} 5=$ flow triggering at $1 \mathrm{l} / \mathrm{min}$ and $5 \mathrm{l} / \mathrm{min} ; \mathrm{Pr}=$ pressure triggering; $C P A P=$ continuous positive airway pressure.

istances, as well as for $\triangle \mathrm{EELV}$, irrespective of the mode of ventilation. No variations were recorded in the subjective compliance of the patients by changing the triggering systems (fig 4). In particular, all the trials of ventilation were well tolerated. The pressure-flow re-
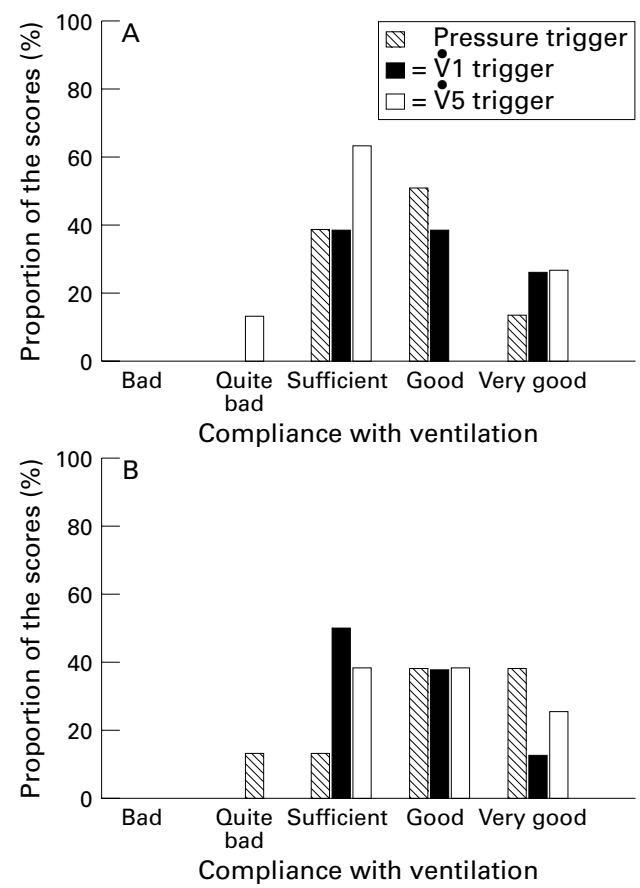

Figure 4 Histograms showing the proportion of compliance scores for each patient with the various ventilatory modes. (A) Pressure support ventilation; (B) assisted/controlled ventilation. 
lationship of the apparatus (face mask and pneumotachograph) was recorded in our laboratory and fitted into Rohrer's equation. The dead space was calculated as $33.9 \mathrm{ml}$.

\section{Discussion}

In this study we present evidence that, in patients with COPD undergoing NIMV through a face mask, the effort of the inspiratory muscles is significantly lower with flow triggering than with pressure triggering in both PSV and $\mathrm{A} / \mathrm{C}$ modes.

The importance of the triggering system during mechanical ventilation has long been recognised in several studies performed in intubated patients. ${ }^{91112} \mathrm{~A}$ consistent portion of the inspiratory effort is a result of the muscle tension necessary to trigger the ventilator but, with the exception of one study carried out in normal subjects breathing through a mouthpiece, ${ }^{10}$ to our knowledge no studies have been performed to assess whether this is also true in patients non-invasively ventilated. The triggering system may be even more important in these patients since, even in a phase of severe acute respiratory failure, they are ventilated in an assisted mode to avoid the risk of sedation and the possibility of patient-machine mismatching.

Surprisingly, only a small proportion $(6 / 21=$ $28 \%$ ) of the portable ventilators specifically designed for NIMV are equipped with flow trigger systems. ${ }^{19}$ In fact, all volume preset ventilators are equipped with a pressure trigger with a maximal negative sensitivity set at $-1 \mathrm{~cm} \mathrm{H}_{2} \mathrm{O}$ (except one in which the maximal sensitivity is $-0.5 \mathrm{~cm} \mathrm{H}_{2} \mathrm{O}$ ), as was the case with the one used in the present study. Most of the pressure preset ventilators (four out of six) use a flow trigger system based on the bias flow or flow-by principle.

The pressure-time product represents an indirect index of the oxygen consumption and the metabolic work of the respiratory muscles. ${ }^{17}$ In this study we have shown that the "total" PTP was reduced by about $20 \%$ with the flow triggering systems, and this reduction was mainly due to a decrease in the pre-triggering phase. This phase consists of two components - one due to overcoming the so-called intrinsic PEEP and one to the effort necessary to open the inspiratory valves - so the contraction of the inspiratory muscles needs to overcome both these components as well as the resistance of the circuit. The bias flow system is designed to provide continuous high gas flow and therefore, even though our study was performed at zero PEEP, this system provided an amount of external PEEP which was quantified at 2.2 (0.2) $\mathrm{cm} \mathrm{H}_{2} \mathrm{O}$. The addition of external PEEP during NIMV has been shown to decrease inspiratory effort significantly in stable $^{7}$ or acutely ill $^{8}$ patients with COPD and this may therefore explain the reduction in PTP observed during flow triggering.

The PTPoes depends, however, not only on the deflection in Poes before the first zero flow point, but also on the time it lasts. This time averaged $79.7 \mathrm{~ms}$ for PSV flow trigger and
89.1 ms for PSV pressure trigger. Furthermore, it has been suggested that the abdominal muscles are more relaxed during expiration with flow triggering than with pressure triggering, ${ }^{20}$ and this could also explain the reduction in PEEPi,dyn, but the present study confirms our previous observation ${ }^{7}$ that this phenomenon is rarely seen in patients with stable COPD.

The PTPoes due to the valve opening was reduced with flow triggering and this was mainly related to the time delay in opening the pneumatic system (77 (17) ms for flow during A/C versus 109 (23) for pressure and 89 (18) for flow during PSV versus 117 (27) for pressure, not significant). The PTP opening nevertheless achieved a statistically significant decrease using the bias flow system. This is likely to be related to the smaller deflection in Poes during flow triggering since the improved sensitivity of the valve system may reduce the effort of the patient. The PTP post-triggering was not statistically different with the different trigger systems, except for the $\mathrm{A} / \mathrm{C}$ flow trigger at $11 / \mathrm{min}$.

A theoretical problem in calculating the energy expenditure of the respiratory muscles could be the changes in the mechanics of the respiratory system. However, lung compliance and resistance, together with $\triangle \mathrm{EELV}$, were similar with the various ventilatory modes.

A reduced time delay with flow triggering is expected to reduce the patient's sensation of dyspnoea and discomfort. ${ }^{21}$ Compliance with the ventilator was assessed in this study using an arbitrary score. An overall good tolerance to the various ventilator settings was recorded, and the expected difference in comfort between flow and pressure triggering was not observed. The sensation of dyspnoea has been linked to the inspiratory load, but this is not the only factor related to this symptom, especially if the load is "chronic". ${ }^{223}$ These patients were ventilated from the episode of acute respiratory failure with a pressure triggering system and therefore they were more "accustomed" to this mode; indeed, our score was not specifically designed to assess the sense of dyspnoea, but rather the patient's comfort.

In conclusion, we have shown for the first time during NIMV that, in patients with stable COPD, the effort of the inspiratory muscles is markedly reduced using a flow triggering system compared with a pressure triggering system. This reduction is mainly due to a shortened time delay in opening the valve and to the improved sensitivity caused by the "external" PEEP effect with a bias flow system. The decrease in inspiratory muscle oxygen consumption due to the "trigger variable" was quantified at about $15-20 \%$ of the total energy expenditure. However, this does not seem to influence the patient's comfort during the ventilation.

We wish to thank Dr R C Stenner for kindly reviewing the English of this manuscript. 1 Brochard L, Isabey D, Piquet J, Amaro P, Mancebo J,
Messadi AA, et al. Reversal of acute exacerbations of
chronic obstructive lung disease by inspiratory assistance
with a face mask. $N$ Engl $f$ Med $1990 ; 323: 1523-30$. 
2 Vitacca M, Rubini F, Foglio K, Scalvini S, Nava S, Ambrosino N. Non-invasive modalities of positive pressure ventilation improve the outcome of acute exacerbation in COLD patients. Intensive Care Med. 1993;19:450-5.

3 Bott J, Carroll TH, Conway JH, Keitly SEJ, Ward EM, Brown AM, et al. Randomized controlled trial of nasal ventilation in acute ventilatory failure due to chronic obstructive airways disease. Lancet 1993;341:1555-7.

4 Kramer N, Meyer TJ, Meharg J, Cece RD, Hill N. Randomized, prospective trial of noninvasive positive pressure ventilation in acute respiratory failure. Am $\mathcal{F}$ Respir Crit Care Med 1995;151:1799-806.

5 Brochard L, Mancebo J, Wysocki M, Lofaso F, Conti G, Rauss A, et al. Noninvasive ventilation for acute exacerbations of chronic obstructive pulmonary disease. $N$ Engl f Med 1995;333:817-22.

6 Ambrosino N, Nava S, Bertone P, Fracchia C,Rampulla C. Physiologic evaluation of pressure support ventilation by nasal mask in patients with stable COPD. Chest 1992; 101:385-91.

7 Nava S, Ambrosino N, Rubini F, Fracchia C, Rampulla C, Torri G, et al. Effect of nasal pressure support ventilation and external PEEP on diaphragmatic function in severe stable COPD patients. Chest 1993;103:143-50.

8 Appendini L, Patessio A, Zanaboni S, Carone M. Physiologic effects of positive end-expiratory pressure and mask pressure support during exacerbations of chronic obstructive pulmonary disease. Am $\mathcal{F}$ Respir Crit Care Med 1994;149:1069-76.

9 Henry WC, West GA, Wilson RS. A comparison of the cost of breathing between a continuous flow CPAP system and a demand flow CPAP system. Respir Care 1983;28: 1273-81.

10 Sassoon CSH, Giron AE, Ely EA, Light RW. Inspiratory work of breathing on flow by and demand flow continuous positive airway pressure. Crit Care Med 1989;17:1108-26.

11 Sassoon CSH, Lodia R, Rheeman CH, Kuei JH, Light RW, Mahutte KC. Inspiratory muscle work of breathing during flow by, demand flow, and continuous flow systems in patients with chronic obstructive pulmonary disease. $A m$ Rev Respir Dis 1992;145:1219-22.

12 Giuliani R, Mascia L, Recchia F, Caracciolo A, Fiore T, Ranieri MU. Patient-ventilator interaction during synchronized intermittent mandatory ventilation. Am f Respir Crit Care Med 1995;151:1-9.

13 Nava S, Rubini F, Zanotti E, Ambrosino N, Bruschi C, Vitacca $M$, et al. Survival and prediction of successful ventilator weaning in COPD patients requiring mechanica ventilation for more than 21 days. Eur Respir $\mathcal{F} 1994 ; 7$ $1645-52$

14 Baydur A, Behrakis PK, Zin WA, Jaeger MJ, Milic-Emili J. A simple method for assessing the validity of the esophageal balloon technique. Am Rev Respir Dis 1982;126:788-91.

15 Mead J, Whittenberger JL. Physical properties of human lungs measured during spontaneous respiration. $\mathcal{F} A p p l$ Physiol 1953;5:770-96.

16 Abbrecht PH, Rajagopal KR, Kyle RR. Expiratory muscle recruitment during inspiratory flow-resistive loading and exercise. Am Rev Respir Dis 1991;144:113-20.

17 Field S, Grassino A, Sanci S. Respiratory muscle oxygen consumption estimated by the diaphragm pressure-time index. F Appl Physiol 1984;57:44-51

18 Sassoon CSH. Mechanical ventilator design and function: the trigger variable. Respir Care 1992;37:1056-68.

19 Kacmarek R, Hess D. Equipment required for home mechanical ventilation. In: Tobin MJ, ed. Principles and practice of mechanical ventilation. New York: McGraw-Hill, 1994: $111-54$

20 Urbscheit N, Bishop B, Bachofen H. Immediate effects of continuous positive pressure breathing on abdominal expiratory activity, minute ventilation and end-tidal $\mathrm{PCO}_{2}$ of conscious man. Phys Ther 1973;53:258-64.

21 MacIntyre NR, Ho LI. Effect of initial flow rate and breath termination criteria on pressure support ventilation. Chest 1991;99:134-8.

22 Howell J. Behavioral breathlessness. In: Jones NL, ed. Breathlessness: The Campbell Symposium. Hamilton, Ontario: Ciba, 1992:149-55.

23 Altose MD, Leitner J, Cherniack NS. Effects of age and respiratory efforts on the perception of resistive ventilatory loads. 7 Gerontol 1985;40;147-53. 